\title{
Compared Efficiency of the Class Management Appropriation Skill by Two Categories of Physical Education Trainee Teachers: The Example of Learning Time
}

\author{
Mrayeh Maher'1, Bouzid Med Sami', Naila Bali'1, Jean-Francois Desbiens ${ }^{2}$ \\ ${ }^{1}$ Higher Institute of Sport and Physical Education of Ksar Said, Tunis, Tunisia \\ ${ }^{2}$ Faculty of Sport and Physical Education, University of Sherbrooke, Sherbrooke, Canada \\ Email: mrayeh.meher@hotmail.fr, med.sami.bouzid@gmail.com, naila bali@yahoo.fr, \\ JeanFrancois.Desbiens@usherbrooke.ca
}

Received 19 September 2014; revised 10 October 2014; accepted 28 October 2014

Copyright (C) 2014 by authors and Scientific Research Publishing Inc.

This work is licensed under the Creative Commons Attribution International License (CC BY).

http://creativecommons.org/licenses/by/4.0/

c) (i) Open Access

\section{Abstract}

The purpose of this study is to compare the quality of skill's appropriation of the learning time management by two categories of physical education (PE) trainee teachers coming from two different types of academic training. Ten volunteering teachers of PE with an average age of $23 \pm 1$ years and recently recruited ( 9 months work experience) were selected. Five licensees (ESL) originate from the License Master Doctorate (LMD) and five masters graduates (ESM). It should be noted that chosen teachers have significantly the same working conditions (two sessions of sport and physical education (SPE) per week, 32 to 34 students ( \pm 14 years) per class) and have the same physical or environmental conditions. The observation focused on three sports disciplines (sprinting, gymnastics and handball). Gender and experience in sporting practice of students have not been considered. The results obtained have shown that the ESM develop a control quality much better than their ESL counterparts balanced distribution of learning time, especially regarding the time spent on preparatory situations $(p<0.028)$ and time spent in situations of motor development $(p<0.047)$. Also, it should be noted that the licensee teachers spend more time explaining the objectives and content of the session than their counterparts ESM. However, the difference appears insignificant as to time provided for the organization of the material, the transition to the explanation of the mode of organization, movements, available equipment and to discuss the rules of discipline and security.

\section{Keywords}

Compared Efficiency, Level of Appropriation Skill, Management Class, Learning Time

How to cite this paper: Maher, M., Sami, B. M., Bali, N., \& Desbiens, J.-F. (2014). Compared Efficiency of the Class Management Appropriation Skill by Two Categories of Physical Education Trainee Teachers: The Example of Learning Time. Advances in Physical Education, 4, 208-223. http://dx.doi.org/10.4236/ape.2014.44025 


\section{Introduction}

In most of the countries, in North America and Europe, the academic training for educational jobs knows, in the last few decades, many transformations. The successive reforms of the training systems as well as the content of programs succeed one another, since 1970, as in the U.S., Canada, France and in several other countries. On its side, Tunisia did not miss this event; it has been held to a change of training curriculum engendered by a reform of the educational system in 2006 and this, for the purpose to align international guidelines. This reform brings the teaching environment to ask questions about the effectiveness of such a change. In this sense, the present work focuses on the effects of the change of the curriculum for the training of physical education teachers on the quality of acquiring the professional skills, more particularly on the management practices of trainee-teachers class.

In fact, managing a class is very important both for the quality of the teaching and for the learning of pupils (Martineau \& Gauthier, 1999). It is considered as the weakest link and the pivot of the teaching profession (Desbiens, 2008). Also Jones \& Jones (1995) have shown that this skill would be crucial to determine the success of the teacher, regardless of the performed measurement (measure on the grades or the learning achieved by students). For a long time, the school policy makers make reference as implicit criteria in the evaluation of teachers (Nault \& Fijalkow, 1999). According to Martin and Baldwin (1996), success in controlling one's class allows creating a climate of healthy learning, focusing on the pupils, and maximizing the time of learning. This skill would dictate the success of the teaching career as well (Nault \& Fijalkow, 1999). In addition, several studies show that the problems encountered by the new teachers would be in a large part related to the class management (Perrenoud, 2001; Martineau \& Vallerand, 2008). The research indicated that unlike the experienced teachers, beginners have more difficulties to motivate pupils, to promote a climate of optimal learning, to respond effectively to the disruptive behavior of the student and to establish and maintain an effective disciplinary management. According to Durfour (2009), the management of class refers to a well-developed set of skills and strategies produced by the teacher.

In this perspective, the studies carried out by Reynold (1992) in this regard, reveal that the class management difficulties that appear among the novice teachers result from their lack of ability to solve the problems that have occurred in class. Archambault \& Chouinard (1996) and Bali et al. (2014) add that a number of skills are necessary to resolve the problems of classroom discipline which would upset the progress of activities. However, the internship is proven important in the measure or it stimulates to find solutions or the trainee is nested and therefore the acquisition of the necessary skills is to create a favorable climate for learning this that confirmed by Perrenoud (1996).

The training in physical education (PE) today is oriented toward the development of professional skills. In the majority of western countries, the training of PE teachers is structured around a number of skills established according to the characteristics of each country. In physical education, training by competence alternates theoretical and practical courses or the course of teaching practice in the school environment (stage of preparation to professional life) is decisive in the training of PE teachers. The class management is regarded as one of the key competencies, essential in the teaching profession (Nault \& Fijalkow, 1999). Several researchers agree that a professional competence develops in practical situation (Perrenoud, 1996; Colsoul, 2009; Leriche et al., 2010, Leclercq, 2013; Bali, 2013).

In fact, the alternation of theoretical knowledge and practice through the experience, allows the construction of professional skills (Bali, 2005; Greenhouses et al., 2006). The internships in training are proving to be the conducive place likely to develop these skills. Besides, the student has the opportunity to experience situations of dilemma which will bring him/her to build an identity, but also acquire professional skills (Roux-Perez, 2005; Ria et al., 2001).

In Tunisia, the educational system has undergone crucial structural changes. The adoption of the LMD system has been at the origin of many changes in the training of PE teachers, including a reduction in the duration of training and therefore the reduction of the time allocated to the intership.

Should these changes not have an influence on the training and more particularly on the development of the competence of management in class? Starting from this observation, we have chosen to study the degree of mastery of class management competence among teacher trainees from both curricula of different formations. 


\section{General Context and Problematic}

\subsection{Evolution of the Training in Tunisia}

During these past few years, the Tunisian educational system has undergone crucial structural changes; the policies and objectives have evolved by providing innovations in the field of university education. In the field of the $\mathrm{PE}$, the adoption of a new curriculum for the training of PE teachers is reflected by the substitution of the controlled regime by the LMD regime.

The old system provided four-year training including courses of preparation for professional life during the second cycle of university while the new system has adopted currently a three-year training crowned by a course of consolidation and reinvestment practice of theoretical training. Before the adoption of the LMD, training curriculum at the beginning of 2006, there were two particular pathways of essential training in higher institutes of Sport and Physical Education (ISSEP) of Ksar Saïd Tunis, Sfax, Kef and Gafsa for the stakeholders in quality of teaching PE. So, the first concerns the masters of $\mathrm{PE}(\mathrm{Bac}+2)$. The training in this sector was crowned by the university degree in PE for the teaching of PE in primary schools. The overall time volume allocated to this training is from 1690 hours, 949 hours are devoted to the teaching practice which is around $56 \%$ of the overall hourly volume. The training presents $91 \mathrm{~h}$ of course preparing them for professional life in order to obtain the completion of study diploma. The second concerns the professors of PE $(\mathrm{Bac}+4)$. This training will be completed by the obtaining of the Masters in PE and the graduates of this chain exercise in the secondary schools. The master overall volume schedule in PE is of $3120 \mathrm{H}, 1573 \mathrm{H}$ of which are allocated to the teaching practice that is around $50 \%$ of the overall hourly volume. To obtain the diploma of completion of study, students must perform $182 \mathrm{H}$ of internship.

The need to obtain the masters degree is to be able to teach in secondary schools and the diploma of university study to be able to teach in primary schools. The recruitment by the Ministry of Sport and Physical Education was done automatically without any competition for all graduates wishing to join the teaching profession of SPE in schools.

\subsection{A New Training Curriculum: The System License Master Doctorate (LMD)}

A new regime of university training, the LMD system, was established at the beginning of 2006. This innovation is part of a reform to the European level in the framework of the Bologna process, inspired by the anglo-saxon system. This system of education is structured by a new architecture of the curriculum (License: 6 semesters; Master: 4 semesters; Doctorate). It is therefore to retain only three levels of graduates in academic institutions. This resulted in the disappearance of the general university study diploma (which was to Bac+2) and the masters $(\mathrm{Bac}+4)$ as well as the DEA (diploma of advanced studies, Bac+6).

It is for the Department to "set a system of flexible training and comparable to international systems prevalent" J. O. of 30/9/2008 NO. 79. The main objective of this reform is to hoist all the university system at the level of the international criteria, by favoring the equivalence of Tunisian diplomas with foreign graduates and to adapt training to the needs of employment through the professionalization of university studies. The LMD system will also aim to reform programs and to diversify the routes in the promising niches.

However, we emphasize to this effect that no research has been done on a national scale to check the compatibility of the scheme, that is important for western countries, with the socio-cultural conditions and teaching of Tunisia. In this regard, the first operation that was initiated by the trainers of the ISSEP was to seek the preserverance of the same professional skills developed among the nationals of the former regime (Bac+4 years of studies) through the same content of training intended to licensees $(\mathrm{Bac}+3)$. In addition, despite the orientation of the Department toward a professional training of physical and physical teachers, the official programs imposed by the Tunisian Ministry of Higher Education and the Ministry of Sport and Physical Education make no reference to any explicit professional competence.

To return to the training of teachers of SPE in tunisian higher institutes of sport and physical education (ISSEP), the LMD reform has resulted in a decrease of the overall schedule of the training of $831 \mathrm{H}$ compared to the old regime of control $(\mathrm{Bac}+4)$. Thus, this training which is controlled by the formal national programs, fixed the obligation to perform 112 hours of internship in the schools. The reports of the end of the year carried out in 2009 by all the courses supervisors of preparation for professional life, and trainers to assess the students of the graduating classes at the end of the traineeship in preparation to the professional life of the ISSEP Kef and Gafsa 
as well as the reports of investigations in 2010 made to the persons who participated in the design of new programs show a deterioration of the practical training (in terms of lesson-developed skills) of new teachers, which does not meet the objective aimed at by the LMD reform.

The institutional component is of a particular importance. In fact, it has the central power of the educational institution and constitutes the framework reference for the activity of the teacher and this through programs, both at the level of their design that of their implementations.

The programs of the discipline show all of the objectives, aims at achieving and the skills to acquire by students. They, in fact, represent a general framework in which to develop the practices of interventions, which is intended to give students the teaching content of the discipline. However, the programs, referring institutional, secure well the general objectives and propose a number of skills to learn, but they do not specify in detail what the student must learn. In effect a wide margin of freedom is left to the teacher trainer, in compliance with the framework of the broad lines of the programs, to design the content and specific skills. Because of this, the practical knowledge and theoretical, which help to develop the professional skills necessary to the exercise of the teaching profession, mainly the competence of management and that the teachers of the ISSEP choose to teach and develop are not mentioned directly in the official texts.

\subsection{Problems and Issues of the Research}

The reform in Tunisia in university training began in 2006. It had as a main objective the development of a repository of specific and general professional skills. Thus facilitating the vocational integration of these graduates. However, it is to point out that other sectors, such as the studies in medicine and engineering schools have escaped this reform by the fact that they are convinced that a duration of 3 years of studies is not sufficient to develop the specific skills of these two fields of intervention.

In fact, and as regards to the field of sciences and techniques of physical and sporting activities, we have moved from an academic training of four years and which is realized by obtaining a Bachlor degree to a training of three years, realised by obtaining a master Degree conclusive by the award of a diploma of basic license in EP. This change is reflected by a decrease in the overall volume devoted to training, from a total of 3120 hours, 2268 hours for the new system LMD, as well as by the nature of the profile of the Baccalaureate oriented to the ISSEP. It is to be noted that, during the periods that preceded the reform of 2006, the access to the ISSEP was through a competition of entry based on a battery of specific tests for the assessment of physical skills of Baccalaureate candidates belonging to different sections (experimental sciences, maths, arts etc.) and followed by an oral interview.

This selection test guaranteed to better the basic conditions for the success of future teachers. By integrating this new regime (LMD), the procedures for access to the ISSEP have changed also. Only candidates with their tray section sport are oriented by the ministry of higher education and will have therefore the possibility to follow their academic studies in the ISSEP. However, the programs for academic training in the ISSEP developed by Tunisian experts do not describe explicitly the repository of professional competencies of pedagogical intervention and didactic in EPS, which leaves the field open to the trainers to develop, Haut du formulaire either to the actions of training non-targeted and non-contributing to the harmonious development of the potential pedagogic and didactic of teachers of EPS desired, either to actions of trainings showing a certain redundancy of skills to develop among future pedagogic frameworks during the teaching of various training modules.

\subsubsection{Justification of the Choice of the Concept "Classroom Management"}

Today, classroom management encompasses the whole of purposeful and simultaneous actions that the teachers perform to establish a good working climate, create a favorable learning environment (Nault \& fijalkow, 1999). Limiting more to the management of the indiscipline, classroom management includes the development and regulation of the use of physical space, time and equipment in all its aspects as well as the management of the group of the student. The application of the rules of life and the interventions to prevent and correct the misconduct are also part of the concepts of classroom management (Desbiens, 2006). Since that time, it became a formally recognized competence including a set of professional practices distinctive and constitutive of the practice teacher, many countries including North American and some European countries, have made the management of class an object of systematic training in the framework of the training of future teachers of physical education (Desbiens, 2006). 


\subsubsection{Importance of the Jurisdiction the Management of Class during the Teacher Training}

In the field of vocational training, the importance given to the professionalization of traineeship in duration and form is crucial to the development of competence relative to the management of class especially in the teaching profession. Such an exercise of pedagogical intervention is considered by Tardif (2006) as being a source of knowledge, of experience, also considers as the basis of the professional competence of teachers of business. On his side, Colsoul (2009) claims that wrestling with the changing realities of the class, the trainee would be faced to the opportunity not only to try but also to put in test the fruit of reflection primed beforehand in the activities carried out within the institutions of training. Moreover, Perrenoud (1996) considers that the disciplinary management of the class remains the greatest challenge of the teacher trainees, and it is not uncommon to see ask for beginners and this of their first not in class, to accomplish the same tasks that the teacher who has accumulated several years of experience. However in Tunisia, this professional skill has not really created the direct interest of researchers and it is treated secondarily in initial training and would rather be the subject of occasional aid (in case of need), on the ground and then raise the educational advisers or inspectors. Only research on certain components falling within this jurisdiction has been the subject of studies, such as the feedback, the indiscipline, time management and equipment.

We also emphasize that the time allocated to the trainee teacher is decreased from 182 hours to 112 hours with the introduction of the LMD system. For comparison, in Quebec, the teacher training programs of EP allocate 700 hours of practical training sessions in classes (for a curriculum of 4 years), and in France 360 hours are devoted to a curriculum of 5 years. Because of this, the end-of-course report emphasizes enormous difficulties at the level of teaching empowered students trainees during the training in preparation for professional life. The time management would seem to be little favorable to the learning of the student. The educational interventions of the trainees would seem inadequate to certain situations, which therefore translates into the absence of clear guidelines for management training class in the learning of this essential skill in teaching of physical education?

On the basis of these findings, we chose to study the quality of acquisition of the competence of classroom management, by teachers from EPS from 2 curriculum of different training (curriculum LMD and curriculum mastery).

\subsubsection{The Time Management}

Several researchers in the field of education have defined the management of class as a set of strategies and procedures necessary in the establishment and maintenance of an environment conducive to the teaching and learning (Martineau \& Gauthier, 1999). In this regard, the management of time is revealed among the indicators likely to promote the smooth functioning of the class. The analysis of the component time allows you to determine the way in which the teacher uses the time devoted to the meeting of EPS.

Taking into account that the useful time is not fully employed in learning, Pieron \& Cloes (1998) reveals that first part would consist in instruction or in information generally intended for the group. A second part is devoted to the practice. Finally, the third and last part is assimilated to transition periods. This distribution is similar to the model of Brunelle et al. (1996). This team of researcher used for the collection of data on time of learning, a system of analysis of the learning time (SATA). This system provides for three categories of situations. In effect, the learning time is structured around three situations offered to the group. The first being the preparatory situations, the second the situations of development of knowledge and finally the last, those dedicated to the development of the engine. Each type of situation comprises set of categories.

The preparatory situations comprise the management, the heating, the organization, transitions, breaks and the return to calm. The situations of development of knowledge imply the moments or the student receives a strategic information, technical, or concerning a regulation or a behavior to adopt (ethics), a supplementary information or on health. Finally, the situations of motor development include the moments where the students are engaged in the practice of activities, it is therefore of strategic skills and techniques, competitive situations and the physical packaging.

\section{Method}

The present study is the result of a repository framework detailing the influence of initial training on the degree of ownership of the competence of management of the class during the meetings of EPS. 


\subsection{Study Population}

For the observation of verbal intervention relating to the behavior of the trainee teacher during the meeting of EPS. We are based on a sampling of convenience which included ten teachers of EPS trainees, volunteers recently recruited (9 months only of professional experience). Five among them are the licensees from the LMD regime and having an average age of $23 \pm 1$ years. The other five, of maitrisards from the tray speed +4 and having an average age of $24 \pm 1$ years.

The selected teachers are continuing their course in colleges of the region of Greater Tunis. They were selected on the basis of the following considerations:

- They have substantially the same conditions of lessons: colleges in the neighboring characteristics both from the point of view number of pupils per class (32 to 34 students), that the material conditions or environmental available for the practice of APS sus indicated.

- The programs of activities are comparable: 3 activities being thus exempted: athletics (sprinting), gymnastics and handball.

- The pupils taught are characterized by an average age of 14 years. The sex and the experience in the field of sport practice of students have not been taken into account.

\subsection{Experimental Protocol}

We have proceeded in the first place for the observation of the educational activities of the trainee teachers on the premises of exercises; thus joining, Leontiev (1984) which stipulates that any human activity is connected consciously or not to the reasons which depend on a specific environment.

\subsubsection{The Observation}

This observation has for aim to analyze the whole of teaching practices used by the trainee teacher in order to install, maintain or restore in the class of conditions conducive to learning and to the development of skills and social behaviors as well as the operation of the class and the activities, the quality of teaching activities, the management of the group and of the social interactions, the order and discipline. These observations have been carried out in the places of exercise of trainees. They have key twenty classes in the first cycle of secondary education with staff from 32 to 34 pupils per class and whose average age is $14 \pm 1$ years. These observations have been carried out in the places of exercise of trainees. They have key twenty classes in the first cycle of secondary education with staff from 32 to 34 pupils per class and whose average age is 14 years.

The data collected relate to the recording (video and audio) of all the actions and interventions of trainee teachers face to their pupils. The data are collected using a camcorder and a wireless microphone. The observer with the camcorder's mission is to follow the trainee in a relevant manner in all its movements. The verbalizating as the trainee is in course of action is collected through the microphone connected to the camcorder. A total of twenty (20) sessions of forty (40) minutes each is filmed. Ten of them concern the trainees licensees and the ten others concern the trainees maitrisards. All sessions filmed are retained for the analysis. We opted for the kind analysis differs in that is to watch the meetings of education on several occasions in order to identify the indicators of the competence of management class, essentially the one relating to the time of learning. The device (pairing "his/image") used when the observation has enabled us to put in relation the behavior of the various actors and the claims of each (instructions, private remarks or collective, verbal reactions and behavioral of trainee teachers as well as students). The trainee teachers were filmed during two meetings before the recording of data in order to accustom the protagonists of the study to the hardware used. All participants are previously made aware of the purpose of our study and of the provisions taken to preserve their anonymity and the confidentiality of the raw data. Their participation is free and voluntary, none has received remuneration for its participation.

\subsubsection{The Grid of Observation}

1) The learning time: The development of items relating to the time of learning are inspired of the observation system of learning time (Sota) of Brunelle et al. (1996). However, we are limited to the types of situation offered to the group.

a) Preparatory situations offered to the group

These situations are characterized by moments or the group of participants is exposed to information and ac- 
tivities which are necessary to the conduct of learning tasks.

- Management

Reserve Time to communicate information which are not related to the learning objectives (announce a sporting event, take attendance, etc.).

- Heating

Reserve Time to the practice of exercises which are intended to prepare the body to make activities more intense in gradually raising its temperature and/or by soliciting the amplitude artículo-muscle, taking into account the requirements of the meeting.

- Organization

Time taken by the teacher to explain the mode of organization, displacement, the provision of equipment, present the objectives and the content of the meeting, discuss the rules of discipline and safety.

- Transition

Time that the group supports to carry out the instructions of organization such as move toward the place of practice, to organize themselves as a group or sub-group, place the hardware, form teams, regroup at the request of the teacher, store equipment, etc.

- Pause Time of

Judgment to allow pupils to retrieve (go drink) or to discuss personal issues that do not have report with the subject matter being taught. Pause Time of judgment to allow pupils to rest (go drink) or to discuss personal issues that do not have a relation with the subject matter being taught.

- Return to calm

Time used for the practice of activities to character sedative on plans cardio-circulo-respiratory or exercises of normalization of the amplitude artículo-muscular (stretching), taking into account the activities practiced during the meeting.

b) The situations of development of knowledge offered to the group

These situations are characterized by moments or the group of participants is exposed to information that are directly in relation with the substance to learn during the meeting.

- Strategy

Moments in which the group of participants receives information on a strategy, that is to say a set of coordinated actions (listen to the explanations relating to a zone defensive; observe a demonstration of a tactical defensive; discuss a form of against fast attack, etc.).

- Technical

Moments in which the group of participants receives information on a technique, that is to say the way to execute a movement in particular (listen to the explanations or observe a demonstration on types of launch, etc.).

- Rules

Moments in which the group of participants receives information regarding the rules or conventions that govern the activity taught.

- Ethics

Moments in which the group of participants receives information related to social behavior to adopt in the conduct of activities (incitement to respect the other, to be honest, to see fair play, etc.).

- Additional information

Moments in which the group of participants receives information which represents some kind of cultural knowledge related to the activity taught (the history of the activity, the record established, the prowess of "Heroes", etc.).

- Health

Moments in which the group of participants receives information related to the practice of the physical activity and the habits of life associated to the well-being and physical condition; to the moralities to respect to take advantage of the effects of an adequate training.

c) The situations of motor development offered to the group

These situations are characterized by moments or the group of participants is engaged in the practice of activities which are in relation with the substance to learn during the meeting.

- Strategic skills

Periods during which the group of participants practice of "sets of coordinated actions" designed to control an action plan individually as well as collectively. The situations of "game headed", "game simulated" (scrimmage), 
"routine of exercises" in which the teacher can intervene at any moment, characterize well the moments reserved to the learning of strategic skills.

- Technical ability

Periods during which the group of participants practice of individual actions in the goal to achieve a technical mastery of gestures that make up a sport or physical activity.

- Competitive situation

Periods during which the group of participants, as a group, are engaged in an activity governed by rules in a context which allows you to claim a victory on itself or on the other.

- Physical fitness

Periods during which the group of participants, as a group, engage in activities which are included in the program as a content and not of overheating such as the workout, stretching, exercises to hand-free or with load, the exercises with light gear (ropes, hoops, etc.) the exercises with partners, respecting the techniques of implementation which can achieve the desired objectives.

\subsection{Statistical Procedures}

\subsubsection{Compendium of Data}

The set of dependent variables related to time of learning have been identified by a grid of observation measuring the time of performance of the duties mentioned above.

\subsubsection{Statistical Analysis}

We used a software of statistical "Statistical Package of Social Science" SPSS 16.0. The threshold of meaning withheld is of 0.05 .

- Descriptive statistics

We have retained the mean, the standard deviation, the percentage, the minimum and the maximum for all the dependent variables studied.

- Inference statistics

Given the small number of observations and the non-normality of the distribution of the whole of the values of the variables, we chose the Mann-Whitney test to compare the values of the variables related to the learning time and the verbal intervention of trainee teachers curriculum LMD with those curriculum mastery.

\section{Results}

\subsection{Analysis of the Delivery of Two Categories of PE Teacher}

In the graph below we are going to proceed to the analytical description of the different components of the learning time represented by the preparatory situations, situations of development of knowledge and the situations of motor development. This description will be based essentially on a comparative analysis of the performance of two categories of profile of stakeholders.

The results shown in Figure 1 allows us to deduce that the ESM have shown a quality control at the level of the balanced allocation of time of learning much better than that of their counterparts ESL, especially as regards the time devoted to preparatory situations $(p<0.028)$ and the time devoted to situations of developments engine $(p<0.047)$. In fact the ESM teachers spend on average $37.93 \%$ of the time of the meeting to the preparatory situations by against the teachers ESL spend on average $53.36 \%$ of the time of the meeting to this situation. As regards the situations of motor development, teachers ESM y spend $48.69 \%$ of the time by teachers, against the ESL y spend $31.13 \%$ of the time. However it is to be noted that this difference is not significant in terms of the time allotted by the two types of teachers to situations of motor development (ESM: 11.33\% and ESL: 13.37\%).

\subsection{Description of the Components of the Time Devoted to Preparatory Situations}

The review of statistical data (Figure 2) shows that the teachers (ESL) spend more time on the management of the group (5.60\%) and to heating (24.79\%) than their counterparts (ESM) who spend $1.08 \%$ of the time to the management of the group and $13.87 \%$ to overheating. These results are realized by the significant difference between the two types of teachers regarding the management $(p<0.045)$ and the heating $(p<0.028)$. Nevertheless, the difference is not significant between the two groups as regards their delivery at the level of the time 


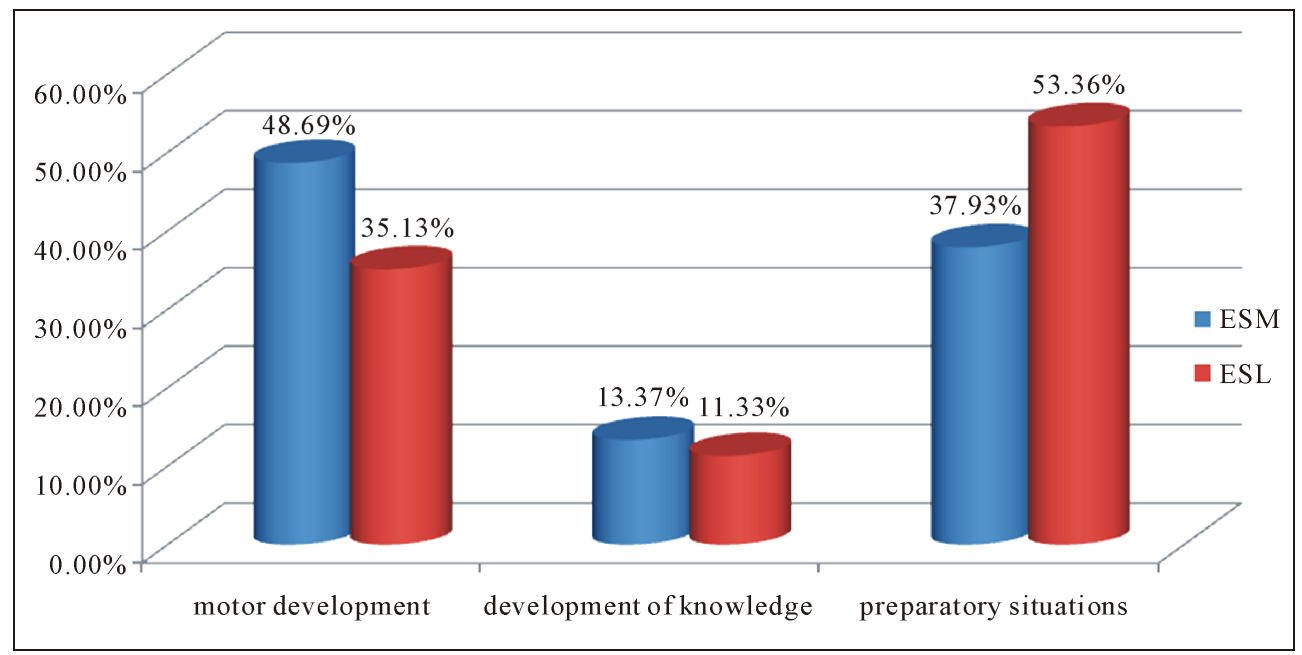

Figure 1. Learning time of a meeting of SPE (\% GST/meeting).

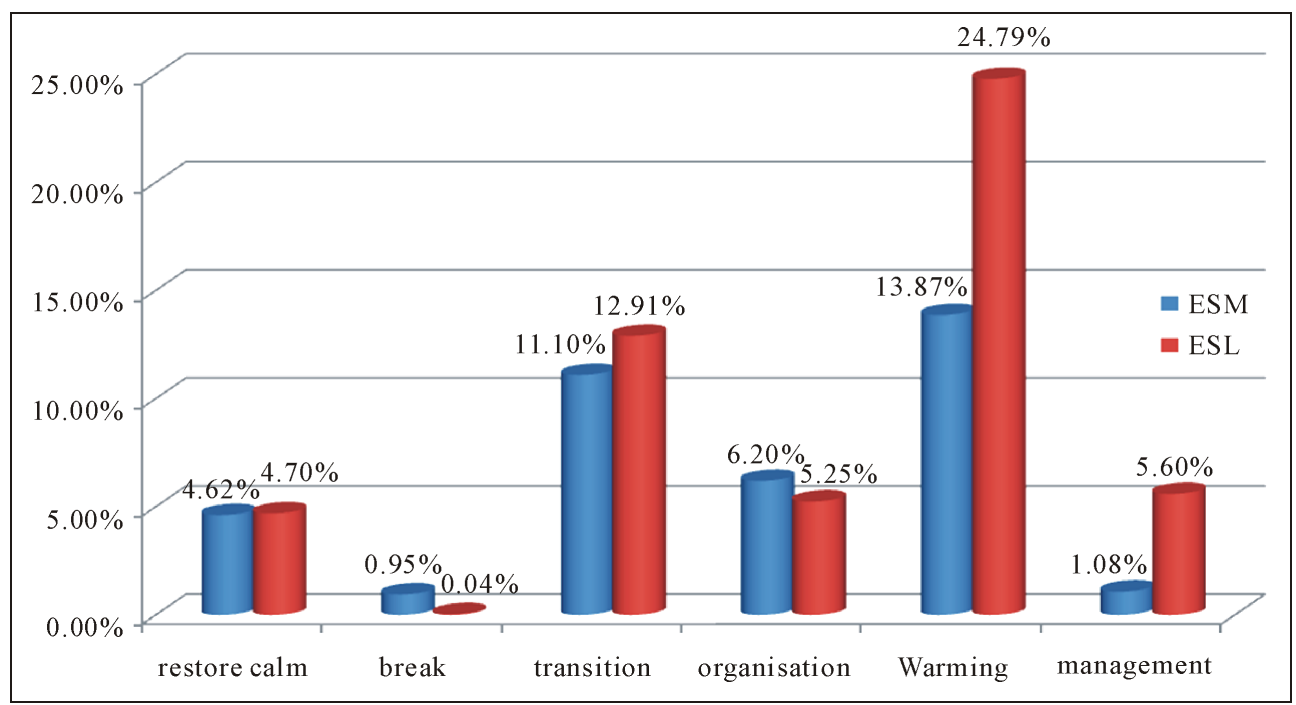

Figure 2. Time devoted to preparatory situations (\% GST/meeting).

allocated to the organization of the material, the transition and the return to calm.

\subsection{Description of the Components of Time Devoted to the Organization of the Meeting}

The analysis of Figure 3 we provided evidence that the teachers ESL shall bring more time for explanation of the objectives and content of the meeting that their counterparts ESM. In fact, with a significant difference between the two groups of $p<0.028$, the teachers ESL spent $1 \%$ of the time with the explanation of the objectives and content of the meeting by teachers, against the ESM spend $0.33 \%$ of the time in this same task. However, the difference is not significant between the two types of teacher concerning the time allocated to the explanation of the mode of organization, to moving from one place to another, to the provision of equipment and to discuss the rules for discipline and safety.

\subsection{Description of the Time Spent on the Situations of Knowledge Development}

The results shown in Figure 4 allows us to deduce that there is no significant difference between the two types of teachers as regards the situations where students are in the process of receiving information on a strategy, technical, regulation, ethics, additional information and health. The two groups on average, spend the same time 


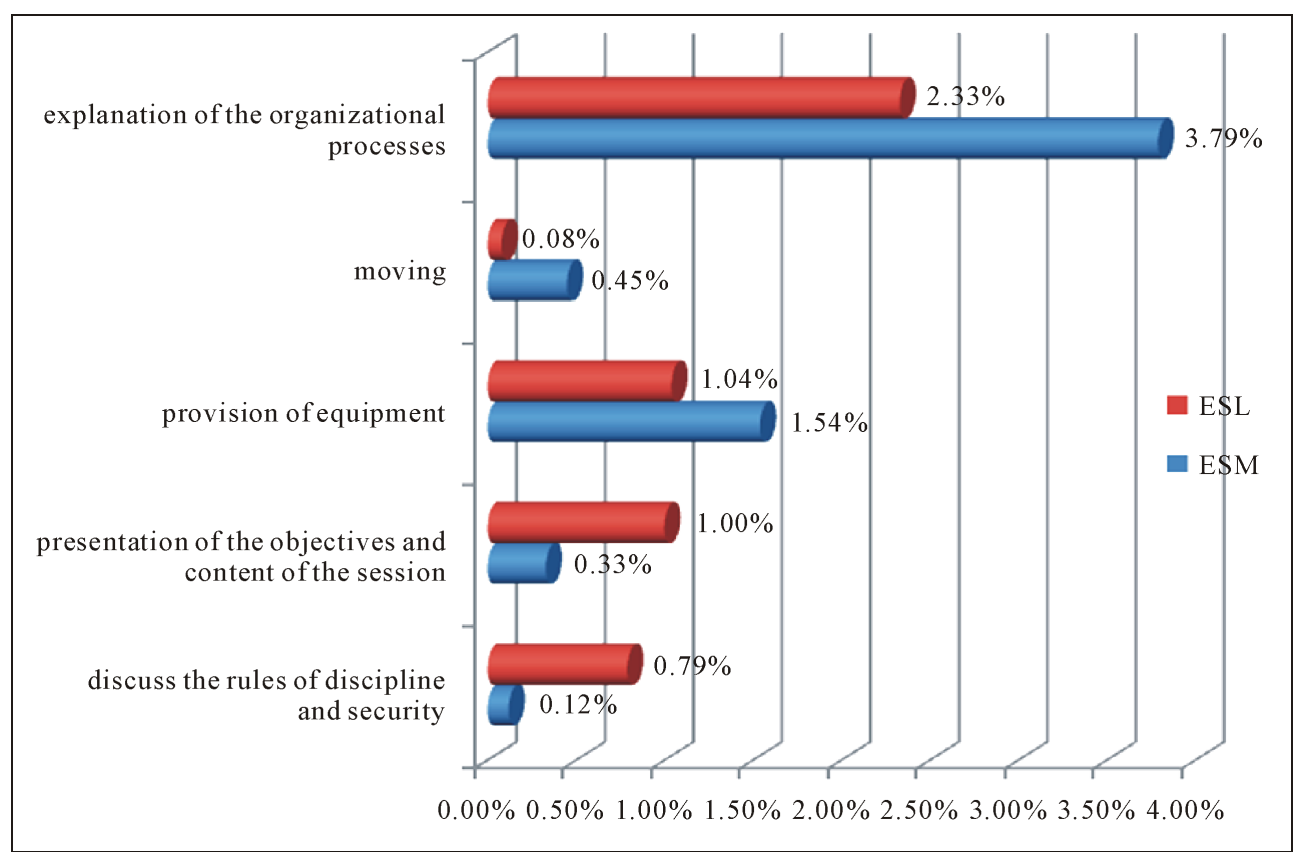

Figure 3. Time spent on the organization (\% GST/meeting).

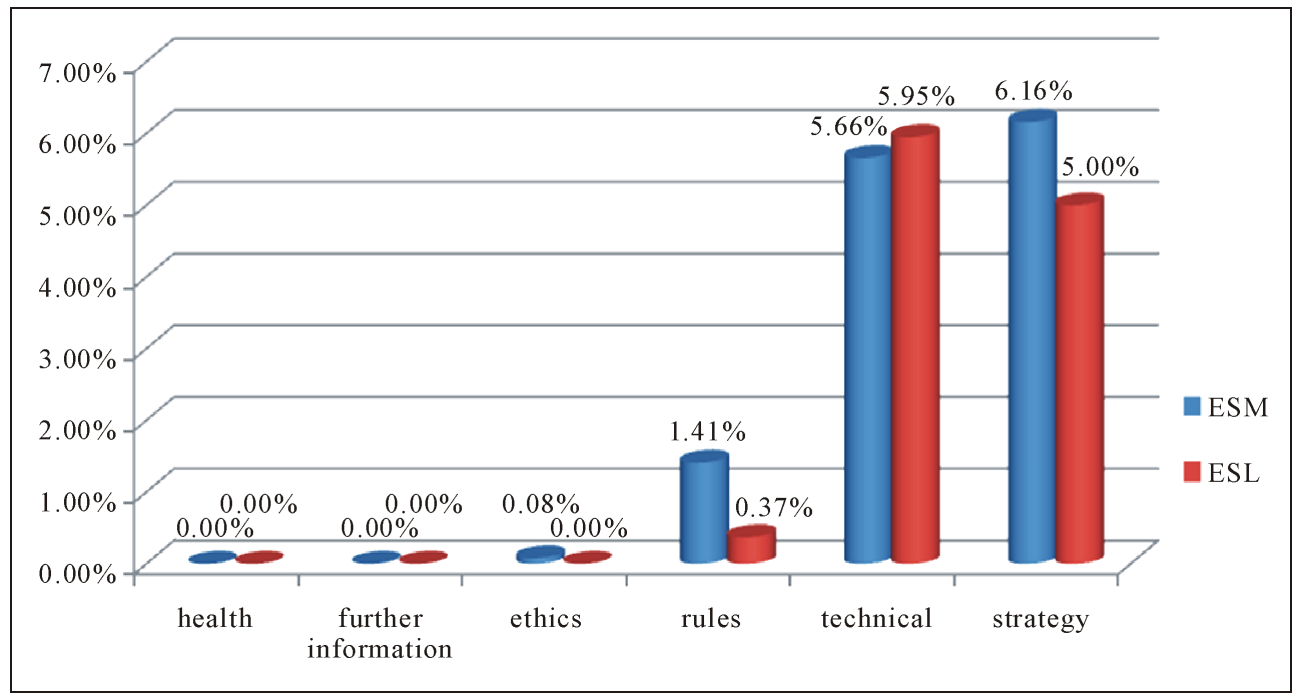

Figure 4. Time devoted to situations of developments of knowledge (\% GST/meeting).

in these situations. However, it is to be noted that the two groups of trainees do not give importance to the ethical categories, additional information and health, given that the time allocated to these situations is to $0 \%$ apart from the category ethics or teachers ESM y spend $0.08 \%$ of the time.

\subsection{Description of the Time Spent on the Situations of Motor Development}

The use of statistical data illustrated by Figure 5, allows us to infer that there is no significant difference between the two types of teachers ESM and ESL as regards the situations of strategic skill, the situations of technical ability, competitive situations and situations of physical fitness. In fact, the two groups spend about the same time in these types of situations. It is to be noted that regarding the category of physical fitness, the results show that the teachers ESL is given no importance ( $0 \%$ of the time of the meeting), while teachers ESM y spend $1.12 \%$. 


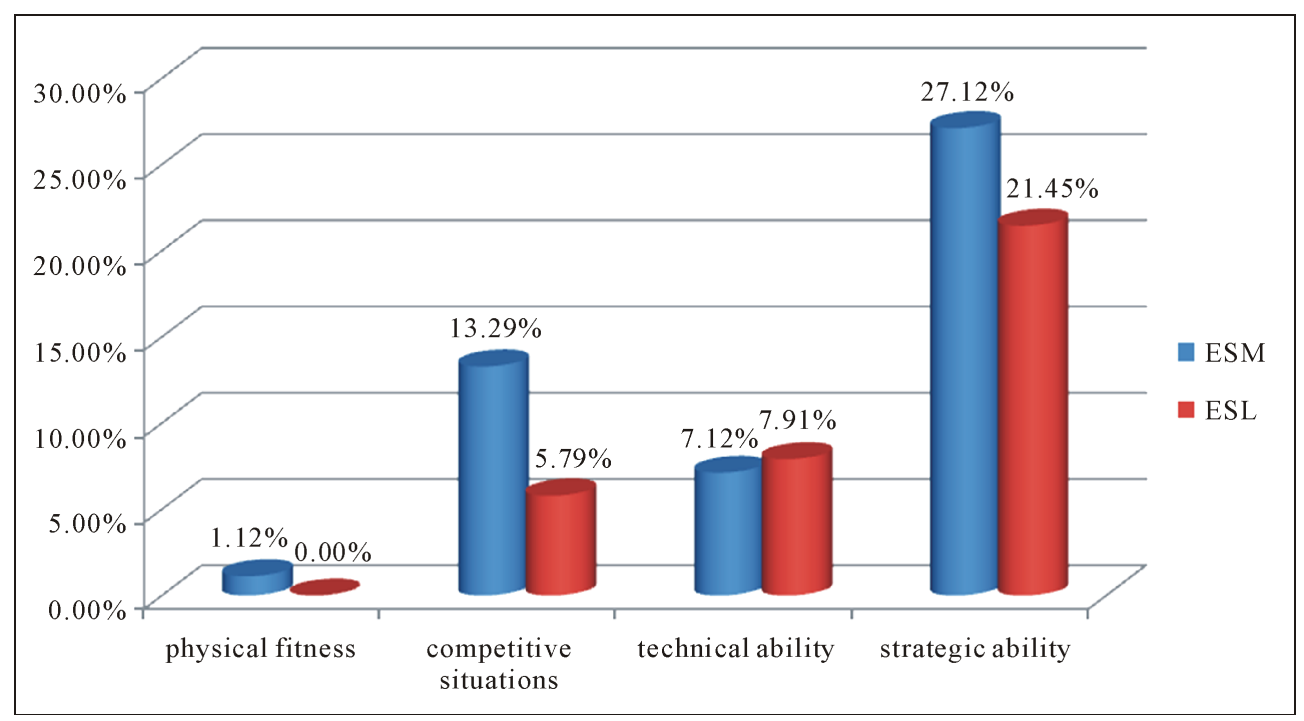

Figure 5. Time devoted to situations of developments engines (\% GST/meeting).

\section{Discussion}

The main object of this study is to pronounce on the quality of ownership of one of the professional skills in teaching of PES among two types of teachers from two regimes of different training. Indeed, the jurisdiction chosen is represented by the ability to manage a class. Such jurisdiction is composed of several complex practices and its quality of acquisition would be greatly influenced by the nature of the training (Lessard \& Schmidt, 2011).

In fact, the results achieved in the framework of this study highlight the differences more than the least significant of the delivery of ESM (E1) and ESL (E2) at the level of certain components of the jurisdiction indicated above such that of the verbal intervention and time management. Indeed, we have found that the teachers (E2) develop skills insufficient to effectively manage the complexity of learning situations unlike (E1) which have developed capacities allowing them to observe the relevant elements of the teaching situations, to treat them and to interpret them in a efficient manner. This efficiency returns to the fact that these teachers are able to use several skills essential in the management of class allowing to ensure a mode of effective supervision and to keep students in the task (Desbiens et al., 2009).

In fact, the recourse to the results concerning the frequency of issuance of verbal intervention individualities does not show a significant difference between the two types of trainee teachers. However, we found differences in the scale of the adaptation of the exercises, the re-explained of the exercise when the latter is poorly executed and the nature of the questions asked by the teacher to the student and this in favor of teachers (E1). These results are justified by Pieron \& Cloes (1998) who asserts that "the lack of experience on the beginners do allows them perhaps not to be able to adapt quickly to situations. They would prefer to adhere to their program and therefore insist on the explanations”. However, this lack of skill necessary to the management of class among teachers (E2) is due, as Durfour (2010) has explained in its research, to the fact that the problems in management of class fall under the inadequate interventions of the teacher. On the other hand, Ria et al. (2003) would justify this by the fact that the beginner does not have a directory of teaching strategies and specific knowledge on the students. It is for this reason that the effectiveness of the teacher says, and essentially requires that the latter should easily adapt to what is going in the class, modify its planning function in the conduct of the activities and of the reaction of the students face to these events and the learning situations (Archambault \& Chouinard, 2005).

However, the difficulties encountered and sus-indicated in fanfold return, after Reynold (1992), the fact that the beginning teachers do not give importance to the techniques of classroom management in the selection and implementation of their solutions. Of this fact, the latter have more recourse to short-term solutions that the assessment of problems and the testing of strategies for long term resolution. As well, instead of adapting the exercises at the level of the student, the teachers (E2) are being forced to repeat several times the explanation of 
the exercise and then move to another situation. According to Ria et al. (2004), the trainees and beginners have difficulties to consider the means to realize their educational intentions. Moreover, they claim that these difficulties are mainly related to their lack of professional knowledge, procedures effective teaching to complete their project. These results are clearly in agreement with what was reported by interviewees according to which the curriculum LMD, having a volume of hours training insufficient, does not allow the acquisition of skills necessary to a good classroom management. They show as well as the trainee teachers could not acquire sufficient knowledge and pedagogical skills in such a short time. However, the construction of professional skills is reflected by an overlapping of theoretical knowledge and practice through the experience (Greenhouses et al., 2006). The internships of preparations in the professional life are precisely the places favorable for the construction and development of the competence of management class.

Therefore the decrease of the time devoted to the practice engendered by the application of the curriculum LMD would be at the origin of the lack of skills to effectively manage the class among teachers (E2).

Similarly, the results also show that teacher (E2) does questionning almost never their students on their benefits. By contrast, the teachers (E1) ask questions to check the good understanding of the student and the move to correct its delivery. Yet according to Archambault and Chouinard (2003), asking questions of the students is a strategy frequently used to keep the attention of students. Thus, in reflective to find answers, they remain active and engaged until the end. In the same vein, Lessard and Schmidt (2011) show that the students in being more aware of the consequences of their actions are more able to make thoughtful choices and appropriate. In fact, resorting to questioning of pupils induced the latter to push further their reasoning, to explain the process that they have used, their understanding the led us to develop their thinking and to deepen their knowledge (Beyda et al., 2002; Richardson \& Fallona, 2001).

On the other hand, interventions to encourage the student to participate more are most often used by teachers (E1). These latter occur also more times to give the student a indication for a successful action. In effect, the (E1) have shown more effectiveness than their counterpart (E2) at the level of this category of intervention of the fact that it is important to raise awareness as students of their involvement in the task, to the fact that they have improved and that the work performed is the closer to the desired goals. This is explained by the fact that the students do not always realize the fact that they develop their skills (Archambault \& Chouinard, 2003). It is also relevant to point out that the students are not all able to control to the same degree the different skills to interact in an appropriate manner, then it is necessary that the teacher helps them to develop these skills in their giving precise instructions to put them into practice. The effectiveness of the teacher is revealed also in the need to make frequent reminders about the skills they want to acquire to their students and to encourage when they apply (Richardson\& Fallona, 2001; Rosenberg \& Jackman, 2003; Smith \& Gilles, 2003; quote in Lessard \& Schmidt, 2011).

With regard to the interventions of feedback, the statistical analysis has shown that the teachers (E2) emit less simple feedbacks, positive and negative as well as less informative feedback positive and negative that teachers (E1). However, the students need to know they are doing well their job, if they are on the right track, if they have improved and whether they meet the expectations. They also wish that their efforts are recognized and want to feel that their teachers are attentive and that they support them. Therefore, a teacher effectively takes the time to make a return on the approach of the high or on its behavior. It should be encouraging it to maintain its involvement and to persevere until the end of his activity or to readjust slightly to better succeed (Beyda et al., 2002; Emmer \& Stough, 2001; Martineau \& Gauthier, 1999; Sigler \& Aamidor, 2003; Walker \& Walker, 1994; Lessard et al., 2007).

The results also show that the teachers laid off were less intervention from type encouragement that their counterparts maitrisards. In this regard, an effective teacher, qualified of fair and equitable, which referred to the success of all students, do not leave the latter to depreciate but encourage them rather to provide the necessary efforts to ensure that they complement each other to the best of their skills the task they have undertaken (Archambault \& Chouinard, 2003). Therefore in general, the teachers from the previous regime are distinguished teachers laid off by a higher proportion of feedback issued. As we have previously pointed out, the feedback represents a decisive element to the learning of the student. Pieron \& Cloes (1998) argues that the performance of the student is deteriorating by the absence of the feedback. Of this fact and in light of the revelations of Carreiro da Costa and Pieron \& Cloes (1998) who assert that the effectiveness of the teacher takes on the proportion of feedback issued and their appropriate character, we are in a position to assert that the teachers (E1) have better skills to promote the learning of the student that their colleagues laid off. 
These conclusions are supported by the interviewee according to which the training of teachers of EPS is no longer able to offer an effective teacher training in view of the acquisition of the skills and effective procedures teaching is necessary to the establishment and the maintains of an environment promoting teaching and learning. In fact, after them the training is a widespread view and the theoretical side has taken over on the practical side. They argue similarly that the reduction of the time spent at the stage of preparation to professional life, place conducive to the development of professional skills, is between other to the origin of the difficulties they would have teachers (E2) in the management of class.

On the other hand, the results do not reveal a significant difference in the level of interventions of discipline between the two types of trainee teachers. Nevertheless a more thorough analysis of this category we to found the differences clearly clear and irrevocable at the level of some indicators relating to the problem of the behavior.

In fact, the results are that the use of criticism takes a importance more marked among teachers maitrisards. In fact, in the literature, some studies reveal the positive contribution of the frequent use of the criticisms and others relate that the quantity of criticisms made by teachers in the course of a lesson is related negatively to the success of students (Evertson, 1989; O’Neill, 1988). Therefore, the use of the criticisms does little not be regarded as decisive indicator of the effectiveness of the teacher.

Added to this, it has been previously cited, that Johnson (1994) stated the lack of skill of junior teachers to manage the class ends sometimes by potential problems of discipline and a reduction in the time spent in learning engendered by the loss of control of the teacher. Thus, a management class of deficient led to indiscipline which would be engendered by the inadequate interventions of the teacher (Kounin, 1970). In our study, the comments relating to the "request to cease" prove more frequent among the teachers (E1) and they are also more frequently to justify their authority. However, the teachers having a master degree use more often the reminders to the rule, they cry more often on the students and the use of threats is proving more frequent among the latter. We infer as well as the teachers (E2) do not provide evidence of effectiveness in the treatment of behavior problems, unlike the teachers having a Bachlor degree which are more discreet and intervene with more of discernment in order not to interrupt the current activity. Reynold (1992) assigned the faculty to intervene in such to of effective teachers and experts unlike the beginners who do not have this ability.

It has also proved that teachers (E1) move closer more often to their pupils and frequently use the silence to avoid the extension of conflict. Has this title, Nussbaum (1992) stated that effective teachers are circulating more in the class, that they are resorting to non-verbal behavior signifiers and that they follow the pupils of the eyes at all times more than do the teachers ineffective. These data show, therefore the lack of skill of teachers laid off to manage the class unlike those who have their Bachlor degree which would tend to not intervene with the student that if his behavior risk of harm in the conduct of the meeting. The teachers (E1) use more often the visual contact by the fact to move closer to the student and the questioning of the student, what Reynold attributed to the effectiveness of the teacher. As well, they are responsible for the continuous supervision of group work and as revealed Wang et al. (1990), these skills fall under the effectiveness of teachers.

These results are consistent also with what Reynolds (1992) advanced: the lack of ability to represent problems occurred in class, to well-defined and to act accordingly would be at the origin of management problems in class for the beginner. Archambault \& Chouinard (1996) emphasized on his side that different skills are necessary to solve the problems of disciplines in class. These conclusions are also justified by the interviewee who as we explained earlier claim that the curriculum LMD does not offer enough time for training necessary for the consolidation of professional skills in the courses of preparation for professional life.

As regards the analysis of the results of the two types of teachers and especially those relating to the management of the time, we referred to the model of Brunelle and al (1996). In fact, we are limited to the types of situations available to the group. This model determines the distribution of the time by three situations offered to pupils. The first concerns the preparatory situations, the second that of development of knowledge and finally the last relates to situations of motor development. In fact, the results of the allocation of time for learning during a meeting of EPS show that teachers (E2) spending more time in preparatory situations compared to that devoted to situations of motor development $(p<0.028)$. However, it is to be noted that no significant difference between the two types of trainees is observed concerning the time devoted to situations of knowledge development.

Actually, these results are not consistent with the guidelines of logical time allocated to each phase of learning in a meeting of EP which stipulate that the effectiveness of the teaching of EP requires that the allocation of time 
should promote the development of the engine of the student (Cloes, 1996). This has been confirmed by, Mckee and Witt (1990), by the fact that the effectiveness of the management of class is reflected by the optimum use of the time devoted to learning. However, the dismissed teachers spend more than half of the meeting to the preparatory situations $(53.36 \%)$ whose $(24.79 \%)$ to overheating. By contrast, among these same trainees, only $35.13 \%$ of the time of the meeting is reserved for situations of motor development. This can be explained by the fact that the teachers from the former regime of university training have had the chance to exercise more in schools within the framework of the course preparing them for professional life (182 hours of training) compared to those coming from the regime LMD (112 hours of internship).

The time devoted to the management of the group is much more important among teachers (E2). In fact, these latter spend 5.6 per cent of the time of the meeting to this task is five times more than the teachers (E1). However this is the time reserved to communicate information which are not related to the learning objectives as take the presences, give the guidelines etc. Therefore an effective teacher must ensure that the students are more available for learning. Because of this, by introducing specific procedures for the conduct of activities such as the entry into class, the movement, the teacher is able to limit the instructions that he must give them, to provide stability and predictability in the class that creates a secure environment and conducive to learning. However, it is to point out that Walker and Walker (1994), Martineau and Gauthier (1999) and later Emmer and Stough (2001) stipulate that the teacher gets the time to the profile of learning by making pupils more autonomous.

Concerning the presentation of objectives and content of the meeting which represents one of the indicators of the organization, we found that the teachers with a master degree spend about 3 times more time to this task that teachers (E1), with an average $1 \%$ of the time of the meeting.

Although the teacher needs to clarify and present its objectives and expectations to plan the conduct of all the activities in the class, it must not dwell on this task. In fact, the educational interventions intended to inform students in relation to the content and the objectives must be brief and consistent with what will be lived in class (Archambault \& Chouinard, 2003).

On the other hand, Ria (2004) explained that at the beginning of the lesson, the teachers beginners sense of anxiety face to which they develop in class of survival strategies in relation with the typical concerns, for example the control of the discipline, motivate students, etc. Thus, to dwell on the presentation of the objectives and content of the meeting is one of the survival strategies. Desbiens (2009) added that the junior teachers and trainees often have insufficient skills to enable a classroom management effective. He reported that these professional deficiencies cause the loss of time.

We emphasize that the shortcomings presented by teachers (E2) to manage the class may raise a few questions about the efficacy of training devices of the LMD system with regard to the improvement of teaching practices of students in initial training. The fact that teachers (E1) often have high enough skills to manage the class effectively, therefore, it cannot be ruled out that the training LMD, has not had the effect of limiting the development of the competence of management of class among the trainee teachers.

It is in fact clear that the curriculum Mastery presented a better training for future teachers of EPS. The training devices must enable the acquisition and development of skills necessary to allow a management class of efficient had view to create an educational atmosphere conducive to learning which is not the case with the LMD curriculum We agree with the idea of Nault and Fijalkow (1999) according to which the management class is learned and developed.

\section{Conclusion}

The adoption of the LMD system by the Tunisian State has resulted in changes in the training of teachers of physical education at the level of the number of years of studies as well as in terms of content of programs established for this passage, which may constitute a favorable terrain for a vocational training non-conclusive on the qualitative level.

In fact, the present research work has focused attention on the manner and quality of the ownership of the professional skills of the share of two types of trainee teachers from two curriculums of different training, a sack and a maitrisard. More precisely, we have operated with a comparative analysis of the quality of acquisition of the competence of management of class among the pedagogic frameworks mentioned above mainly the time of motor learning.

The results obtained allow seeing the differences at the level of the acquisition of the skills necessary for the 
management of class between the two types of trainee teachers. We have seen that the trainee teachers sacked abilities often insufficient to enable to effectively manage the class. Their cognitive automatisms and their knowledge on the procedural level enable them to establish and maintain order, solve problems, initiate and maintain the students involved in the tasks are often inadequate.

The ESL resort more often to the re-explained to the exercise as the latter was poorly executed contrary to their counterparts ESM who, as to them shall carry out more often the adaptation of the exercises. Regarding the interventions of disciplines, the ESL intervene more often for reminders to the rule and they are more often forced to shout on the students to maintain order during the meeting. Tea ESL resort more often to the re-explained to the exercise as the latter was poorly executed to toute disposition contraire to their counterparts ESM who, as to them shall carry out more often the adaptation of the exercises. Regarding the interventions of disciplines, tea ESL agent will coax more often for on to the rule and they are more often forced to shout on the students to maintain order during the meeting.

These results clearly show that the ESL have not acquired enough skills and strategies necessary to the establishment and maintenance of an environment conducive to the teaching and learning compared to their counterparts ESM. This deduction is supported by the results of the discussions which show a decrease of the quality of the training of future teachers of physical education engendered by the application of the LMD system. The repercussions of this change have been clearly felt and noted in the courses of preparation for professional life more precisely at the level of the ability to manage groups of pupils in the meetings of PES. For the future we plan to study the competence of management class from its theoretical context in ranging from the contents of training toward the trainers as well as the trainee teachers.

\section{References}

Archambault, J., \& Chouinard, R. (1996). Vers une gestion éducative de la classe. Boucherville: Gaëtan Morin.

Archambault, J., \& Chouinard, R. (2003). Vers une gestion éducative de la classe (2nd ed.). Boucherville: Gaëtan Morin.

Bali, N. (2005). Articulation "theorie-pratique" dans la formation des eleves-professeurs tunisiens d'education physique: Conceptions des formateurs et des formés. Revue Recherche et Formation, 49, 135-150.

Bali, N. (2013). Teachers’ Thought Processes: The Case of Tunisian Gymnastic University Teachers. Creative Education, 4, 158-164. http://dx.doi.org/10.4236/ce.2013.47A2020

Bali, N. et al. (2014). The Conceptions of Integration of Tunisian Physical Education Cooperative Teachers and Student Teachers. Creative Education, 5, Article ID: 43922. http://dx.doi.org/10.4236/ce.2014.54037

Cloes, M. (1996). Proposition de contenus d'enseignement pour un volley-ball de mouvement au niveau secondaire. Revue de l'Education Physique, 36, 57-65.

Colsoul, A. (2009). Observation du développement de la compétence de conduite de classe chez le future enseignant d’école primaire à partir d'un dispositif centré sur l'analyse qualitative. Recherches Qualitatives, 28, 22-46.

Desbiens, J. F. (2006). La gestion de classe: contextes et perspectives. Formation et profession. Bulletin de CRIFPE, 13.

Desbiens, J. F. et al. (2009). Perception de la fréquence d'apparition des comportements perturbateurs par des stagiaires en enseignement de l'éducation physique et à la santé (EPS). Nouveaux cahiers de la recherche en éducation, 12, 179-193.

Durfour, F. (2009). L'incidence d'un dispositif de soutient en gestion de classe sur les pratiques disciplinaires et le sentiment d'efficacité d'enseignants débutants. Thèse de Doctorat, Psychopédagogie, Université de Montréal.

Emmer, E. T., \& Stough, L. M. (2001). Classroom Management: A Critical Part of Teacher Educational Psychology, with Implications for Teacher Education. Educational Psychologist, 36, 103-112.

http://dx.doi.org/10.1207/S15326985EP3602 5

Evertson, C. M. (1989). Classroom Organization and Management. In M. C. Reynolds (Ed.), Knowledge Base for the Beginning Teacher (pp. 59-70). New York: Pergamon.

Jones, V. F., \& Jones, S. J. (1995). Comprehensive Classroom Management: Creating Positive Learning Environments for All Students (4th ed.). Needham Heights, MA: Allyn and Bacon.

Leclercq, E. (2013). La question de l'excellence dans les parcours de formation: Le cas du dispositif des Cordées de la Réussite. In S. Ertul, J. P. Melchior, \& E. Widmer (Eds.), Travail, Santé, Education, individualisation des parcours sociaux et inégalités. Paris: L’Harmattan, Collection Logiques Sociales.

Leriche, J., Desbiens, J. F., Dugal, J. P., \& Amade-Escot, C. (2010). Analyse de l'accompagnement du stage en responsabilité au Québec et en France: Un regard sur les entretiens post-leçons à l'aide de l'écologie de la classe. eJRIEPS, 19, 71-98. 
Lessard, A. et al. (2007). Rapport sur l'analyse des conditions favorables au cheminement et à la réussite scolaire des élèves en difficulté d'apprentissage en classe ordinaire au primaire. Quebec: Université de Sherbrooke, Rapport de Recherche, Vol 2: Les Conditions liées à la gestion de classe.

Lessard, A., \& Schmidt, S. (2011). Recension des écrits sur la gestion de classe. Quebec: Université de Sherbrooke.

Martin, N. K., \& Baldwin, B. (1996). Helping Beginning Teachers Foster Healthy Classroom Management: Implications for Elementary School Counselors. Elementary School Guidance \& Counseling, 31, 106-113.

Martineau, S., \& Gauthier, C. (1999). La gestion de classe au cœur de l'effet enseignant. Revue des sciences de l'éducation, 25, 467-496. http://dx.doi.org/10.7202/032010ar

Martineau, S., \& Vallerand, A. C. (2008). Les dispositifs pour soutenir l'insertion professionnelle des enseignants. Formation et pratiques d'enseignement en questions, 8, 99-117.

Nault, T., \& Fijalkow, J. (1999). Introduction. La gestion de classe: D’hier à demain. Revue des sciences de l'éducation, 25, 451-466. http://dx.doi.org/10.7202/032009ar

Perrenoud, P. (1996). Savoirs et compétences dans un métier complexe. Paris: ESF.

Perrenoud, P. (2001). Développer la pratique réflexive dans le métier d'enseignant. Professionnalisation et raison pédagogique. Paris: ESF.

Piéron, M., \& Cloes, M. (1998). Recherche en pédagogie des Activités physique et sportives centrées sur l'enseignement primaire et secondaire. Revue de l'Education physique, 38, 109-125.

Reynolds, A. (1992). What Is Competent Beginning Teaching? A Review of the Litérature. Review of Educational Research, 62, 1-35. http://dx.doi.org/10.3102/00346543062001001

Ria, L., Saury, J., Sève, C., \& Durand, M. (2001). Les dilemmes des enseignants débutants: Etudes lors des premières expériences de classe en Éducation Physique. Science et Motricité, 42, 47-58.

Ria, L., Sève, C., Theureau, J., Saury, J., \& Durand, M. (2003). Beginning Teacher's Situated Emotions: A Study of First Classrooms Experiences. Journal of Education for Teaching, 29, 219-234. http://dx.doi.org/10.1080/0260747032000120114

Richardson, V., \& Fallona, C. (2001). Classroom Management as Method and Manner. Journal of Curriculum Studies, 33, 705-728. http://dx.doi.org/10.1080/00220270110053368

Rosenberg, M. S., \& Jakman, L. A. (2003). Development, Implementation and Sustainability of Comprehensive School Wide Behavior Management Systems. Intervention in School and Clinic, 39, 10-21. http://dx.doi.org/10.1177/10534512030390010201

Roux-Perez, T. (2005). Quels processus en jeu dans la construction de l'identité professionnelle chez les enseignantsstagiaires du second degré à l’IUFM? Actes du V Volloque international Recherche(s) et Formation. Nantes IUFM, février 2005.

Tardif, J. (2006). L'évaluation des compétences. Documenter le parcours de développement. Montréal: Chenelière Education.

Walker, H. M., \& Walker, J. E. (1994). L’indiscipline en classe. (Trad. par É. Royer). Lévis: Corporation École et comportement. 
Scientific Research Publishing (SCIRP) is one of the largest Open Access journal publishers. It is currently publishing more than 200 open access, online, peer-reviewed journals covering a wide range of academic disciplines. SCIRP serves the worldwide academic communities and contributes to the progress and application of science with its publication.

Other selected journals from SCIRP are listed as below. Submit your manuscript to us via either submit@scirp.org or Online Submission Portal.
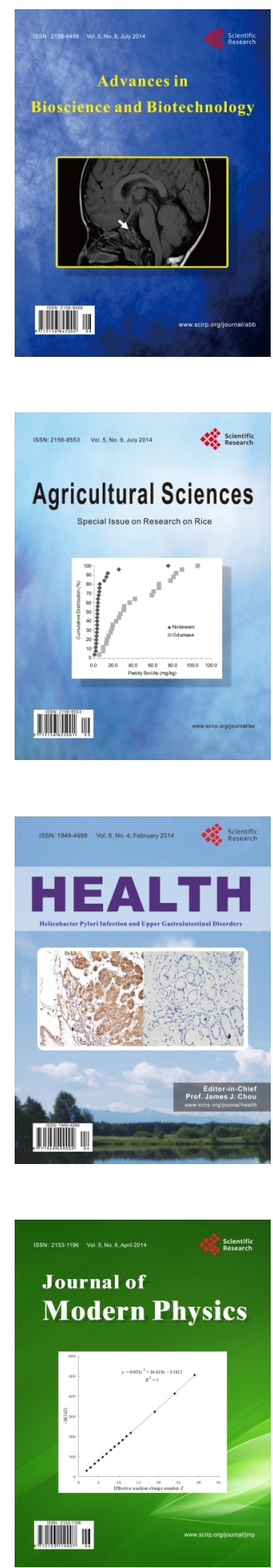
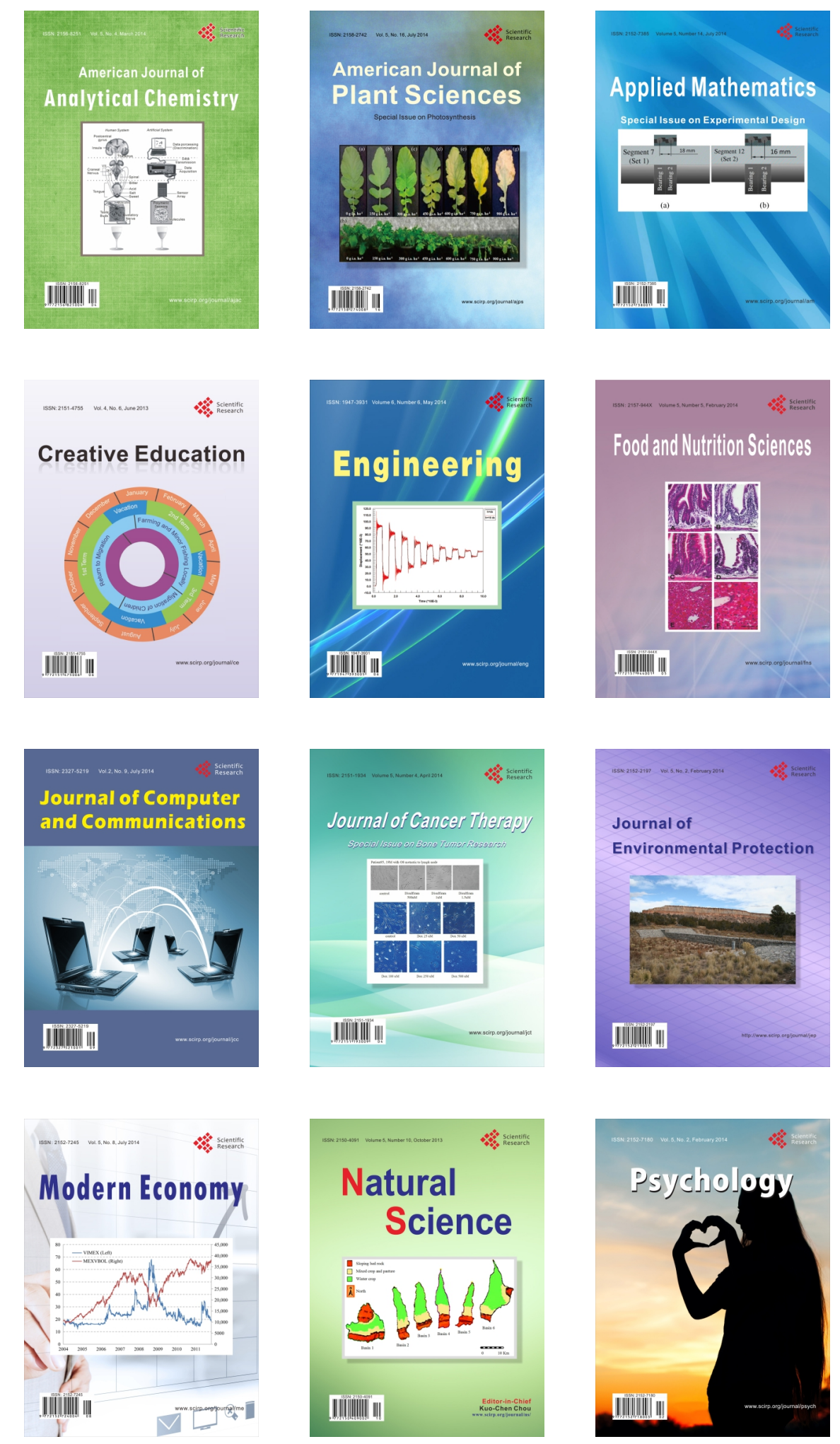